\title{
The Role of Professional Networks in Supporting and Developing Real World Learning
}

\author{
Joanne Brindley and Stuart Sims
}

\section{Introduction: The Changing Context of Higher Education}

It is perhaps an understatement to say that the nature of UK higher education has shifted in the last decade. Not least of these changes is the transfer of the burden of funding higher education exclusively on to students and graduates. Much has been said about the dangers of marketisation and the rise of the student as consumer and potential risks this has for changing staff-student interaction (Molesworth, Scullion, \& Nixon, 2010). In an environment where students' choices and expectations are shaped by an eye-watering price tag for their degree, there is an increasing requirement to ensure that they gain value for these costs (Woodall,

Case Studies: Joanne Brindley, Stuart Sims, Susan Noble and Amy Barlow

J. Brindley $(\bowtie) \bullet$ S. Sims

University of Portsmouth, Portsmouth, UK

e-mail: joanne.brindley@port.ac.uk 
Hiller, \& Resnick, 2014). This value is often determined in a narrow, economically rationalised way which manifests itself in myriad new behaviours ranging from calculating the cost of an individual lecture to expecting to pass without reasonable engagement because they are 'paying for their degree'. In this neo-liberal model that prioritises economic exchange value, inevitably students will be looking at their job prospects and employability. Such an attitude has recently become enshrined as a representative measure of teaching quality by including employment (although importantly not employability) statistics in the Teaching Excellence Framework (TEF) (n.d.).

\section{Expectations of Staff}

While few members of academic staff in universities will be surprised by these changes, what is remarkable is the lack of substantial shifts in how, but importantly also the why of engagement with students. At the thin end of this wedge is making a case of what university is for. Many writers have addressed this extensively and exhaustively without reaching any satisfying end (Collini, 2012). Others have decried that the university is in 'ruins' (Readings, 1996) or other hyperbolic ideas which are hard to confirm without any consensus. One of the few potential ways forward out of these wide-ranging critiques comes from Barnett (2000) who argues that the (or at least a) purpose of the university is to prepare graduates for a super-complex society. Importantly, this is not restricted to 'economy' but rather recognises the importance of graduates being well rounded and adaptable to survive in a rapidly changing information-rich society. To do this effectively, Barnett argues that a move towards an ecological university is required (2017). Such an institution would reflect deeply on its whole role in society and multiple ecosystems within which it sits. Barnett suggests the following range spheres as ecologically relevant to the university: "knowledge, social institutions, persons, the economy, learning, culture and natural environment" (2017, p. 9).

For too long the economic ecosystem has dominated the shape and purpose of universities. In order to rebalance the situation towards prioritisation of the other ecological purposes of the university, there is a need to evoke a change in the way in which we engage with students and how 


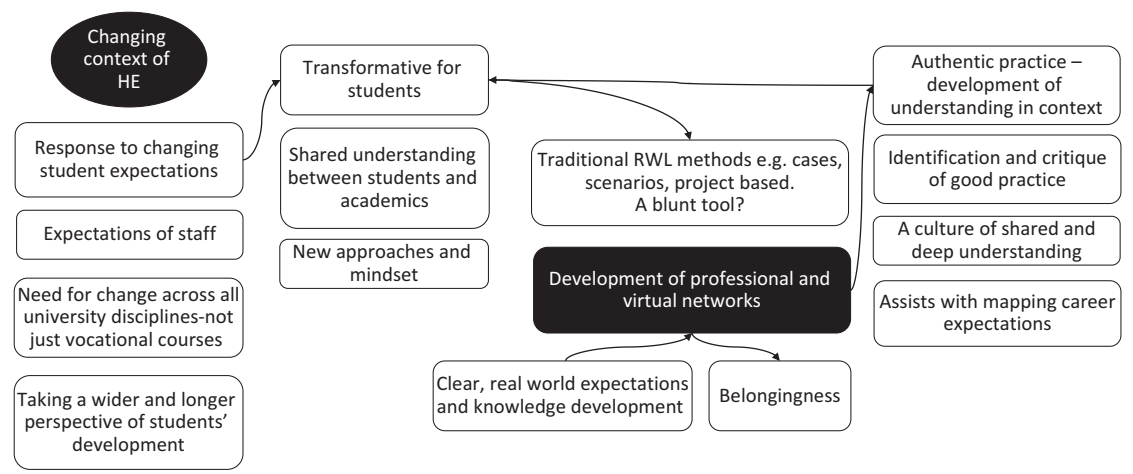

Fig. 3.1 The role of professional networks in supporting and developing real world learning

they reflect on their own priorities. Part of this must come to a necessary broadening of the concept of real world learning. All too often is this seen as synonymous with a narrow economic view, essentially that the real world is only comparable to jobs and often in a tedious and reductionist way.

This chapter seeks to explore how cooperative professional learning networks can be used as a vehicle to rebalance curriculum architecture, bringing a renewed sense of equilibrium to the learning environment, in readiness for the challenges of planning educational experiences which will prepare cohorts for the challenges of future super-complexity, using the key themes identified in concept map (Fig. 3.1).

\section{Developing Professional and Virtuous Networks}

Communities of Practice (CoP) have been identifed by Wenger and Trayner $(2015$, p. 1$)$ as "groups of people who share a concern or a passion for something they do and learn how to do it better as they interact regularly"; encompassed within this definition there is an expectation that an element of learning will occur. However, as Wenger-Trayner clearly state, the occurrence of learning within a CoP cannot always be assumed. 
The central tenet of a Professional CoP (PCoP), within the context of this chapter, is that all members of a structured PCoP have the expectation that the activities they undertake will be embarked upon with express intention that learning and development will be supported by all at its heart. The formation of a PCoP is to create a vehicle in which acknowledged workplace and academic masters alongside novice professionals come together to embark on a process of legitimate peripheral participation (the process of actively participating in communities of practice which facilitates the process of learning and participation, via a social context, enabling novice learners to become experts), which is embedded within a model of situated learning and facilitated via social interaction. The benefits of the coming together to cooperate as a PCoP support the deliberate construction of knowledge and the development of relational and technical skills, which are anchored within the methodised realms of the working world, opposed to a process of cognitive transmission situated exclusively within the academic environment.

Alongside the obvious benefits of a shared PCoP, there are also opportunities during real world learning activities for informal networking with future professional colleagues to occur, acting as a cornerstone which does not seek to influence future job prospects but, instead, becomes a linchpin for providing insight into future pathways via workplace supporters (e.g. mentors, coaches and supporters). This virtuous network allows students to access people who they can draw upon in the present and future to bring a sense of reality and context related to their individual experiences, which are additionally supplemented by the perceived sense of belongingness and value that a PCoP culture facilitates. Indeed, Wenger, Trayner and De Laat (2011, pp. 19-21) and Poole, Iqbal and Verwood (2018, p. 10) have identified the various forms of value which are generated from a $\mathrm{CoP}$ - "immediate value (for example, via activities and interactions which reveal a new perspective), potential value (which is not always apparent at first, but provides 'knowledge capital' which can be drawn upon at a later date), applied value (which has the capacity to change practice, leading to innovation), realised value (the process of reflecting on the application of knowledge), reframing value (leading to transformation of existing practices)" and "aspirational value (which may be open to the influence of others)". 


\section{Authentic Practice}

Academic staff have a pivotal role in identifying ways to support the acquisition of more imaginative real world learning experiences, allowing students to acquire theoretical academic knowledge which in turn can be applied in real world settings. The meaningful application of translating theory into practice exposes students to the challenges of working in contemporary society. This does not occur solely within the act of knowledge application, but also assists in gaining a broader perspective by critically appraising the actions they have taken. Students can then consider the effect(s) their actions have had, allowing cognisance of the tacit norms and appreciations which underpin the situation and the broader organisational context. As Boyer (1990) has identified, if students are inspired to learn and discover more through independent search and inquiry, their learning experiences will become richer. By developing accountable real world experiences, students can explore their actions and beliefs on a deeper level, which will assist them in preparing for future active citizenship.

\section{Developing a Culture of Shared and Deep Understanding}

Education is a process where fledgling practitioners should be facilitated in developing the autonomy to make their own choices based on informed understanding, analysis and critical thinking. The process of being enabled to think critically invites the students to evaluate their own personal learning and create a conscious understanding of how they are making decisions and how this, in turn, is influencing their practice. Therefore, it is essential that educational providers are confident that their students are endowed with these skills, even if this may be uncomfortable to the developing cohort.

Providing an opportunity for the PCoP stakeholders to meet together on a regular basis, either formally or informally, provides a vehicle in which students are able to air and share their views and experiences in a safe space, facilitating the development of attributes required of graduates 
(Cameron, Binnie, Sherriff, \& Bissell, 2015). Reflective group activities are an obvious gateway mechanism to support student development with the main emphasis being placed on reflection around the practice aspect. It is important to remember that the act of reflection should not be perceived as a relaxed meditative process; indeed, critically reflecting on one's own behaviour is a challenging and demanding process (Osterman \& Kottkamp, 1993). Davies and Kremer (2016) have described how reflection on negative or demanding events can enact an acute stress response, generating a flight or fight approach to reflective tasks (Fig. 3.2).

In order to negate using the process of reflection as a confessional or personal crusade, there should be a clear sense of purpose and balance articulated prior to this activity. The PCoP should aim to develop clear rules of engagement. If a clear and shared common language for group reflection is co-created and in place, the PCoP will be best placed to effectively support the development of a collaborative and cooperative environment, with specific focus on the acceptance and support of all

Fight response

Resistant to change

Contradicts all criticism

Attacks the person who has criticised them

Blames process or policy

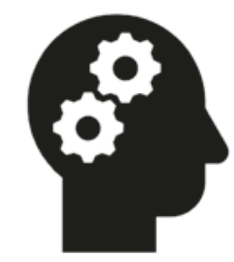

Flight response

Withdraws from the situation

or uses the process as a confessional activity

Accepts unnecessary criticism

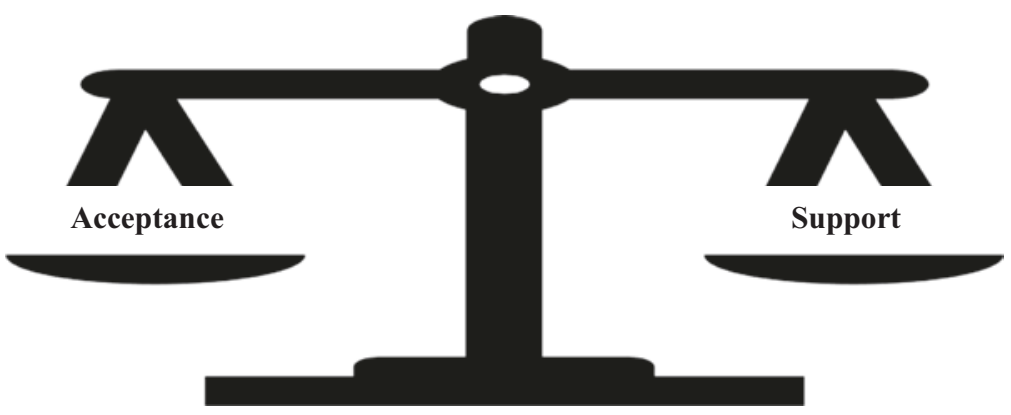

Fig. 3.2 Creating a culture of shared understanding within a professional community of practice. (Adapted from Davies \& Kremer, 2016) 
members, driven by the opportunity to engage in critical dialogue with trusted colleagues. Explicit reflection on experiences allows learners to identify skills gaps, creating a way in which they can articulate their aspirations and learning requirements, informing their studies (Sierbert \& Walsh, 2012) which in turn, allows the course teaching team to deliver bespoke activities in direct response to the cohorts individual requirements.

The exploration of individual experiences via a synergised $\mathrm{PCoP}$ is a necessity which enables all parties to develop a greater level of selfawareness, directly related to the nature and impact of individual performance and that of the wider group. The act of sharing is a catalyst for self-awareness which springboards opportunities for professional growth by enabling acknowledgement of both the emotional and rational dimensions of change (Osterman \& Kottkamp, 1993) which are quintessential in supporting the development of a deep understanding. Taking time to verbally participate in group reflective activities can then be used to inform a written action plan or to identify professional development activities.

\section{Knowledge Development and Real World Expectations}

Learning is not an isolated occurrence but a ubiquitous coalescence of our own practices, personal perspectives and underpinning values which have arisen directly from our own prior experience. Professional learning experiences are an essential part of our development, informing what we do-underpinned by the instinctive insight we have into how we feel we should act in any given situation. As such our values and beliefs form an important part of this process. Jarvis and Watts (2012, p. 361) identify how the learning process has participation and practice "at its heart", describing how the motivation for learning is to move away from the "mundane sense of just getting through the day" and the desire to move towards the value-laden process of "living a worthwhile life". Taking time for professional reflective practice provides a way to step outside of our professional values and beliefs in order to critically examine how we are 
involved in creating social or professional structures counter to our espoused values. It enables awareness of the limits of our knowledge and how our own behaviours are complicit in our organisational practices bringing into alignment the contemporary professional practice. This can be achieved by taking the time to look back on workplace activities, both extraordinary and routine, to identify if there is any action that can be made which allows a vision of practice to be improved upon and further enhanced. Reflective activities are a key component in reviewing and achieving this change.

\section{Case Study 1 \\ Effectiveness of Regular Practice Team Meetings to Support Reflection and Insight in Readiness for Primary Healthcare Practice with Dental Students and Staff (Joanne Brindley, Senior Lecturer in Education and Academic Lead, University of Portsmouth)}

\section{Context}

The aim of the University of Portsmouth Dental Academy (UPDA) was to develop a unique, innovative, team-based approach to dental education in a primary care setting, opposed to the more traditional secondary (hospital-based) educational delivery. The students at UPDA are inplacement students who are joined annually by a final-year cohort of out-placement dental undergraduates from King's College London Dental Institute (KCLDI).

\section{Intervention}

The introduction of the KCLDI students (which commenced in 2010, resulted in the formation of four Practice Teams, with each team having a balanced skill mix of not only students from various programmes but also academic, clinical, administration support and technical staff). Each Practice Team worked closely on the live clinical floor where they were encouraged to refer patients to one another (dependent upon individual 
patients' treatment requirements with a view to supporting skill acquisition) during the week. These activities were supplemented by weekly Practice Team Meetings (PTM) when individual teams' performance and progress was captured. The PTM provided an opportunity to discuss and reflect on experiences with the full range of dental team members, allowing exploration of concerns, successes and failures from a 360-degree perspective, mirroring activities which are expected to occur in the working world. The PTM provided the students with their first insight into the influence and impact that each team member elicits, effecting insight into the overall experience, supporting the identification of audit and student research project opportunities, facilitating reflective discussion about the week and identifying any shortfall or areas of good practice in relation to patient management. In order to optimise the effectiveness of the PTM, each Practice Team had three leads (clinical, academic and student). The leads were responsible for setting out a shared vision for the team identity, processes, meeting agendas and social events. The development of the PTM generated a unique opportunity for students, studying various dentistry based programmes (across differing levels of academic study) to share their thoughts, ideas and experiences, with not just their peers but also the wider dental team, in essence encompassing the three components of communities of practice (Lave and Wenger, 1991): domain, community and practice.

The regular PTM allowed members from each team time to form a professional rapport with one another on a regular basis over an extended period of time. During the meetings all team members contributed to reflective discussion about the week's events. Whilst this scenario was beneficial for the majority of students, for example, those who have good networking skills, there was a need to ensure that clear expectations and rules were set out by the PTM leads so that those students who may not perceive themselves to be 'strong students' were disadvantaged. Each team adopted a 'what is said in the team stays in the team' approach for their reflective discussions. Indeed, research conducted on their reflective activities identified that the students were positive about the benefits of discussing their experiences with one another describing how they preferred to reflect due to the 'informal' nature when 'discussed between teams'. This recognition of being part of a Practice Team underpinned the importance of a perceived safe environment in which to share 
individual experiences, assisted by the sense of belongingness which developed during their programme underpinned by self-actualisation (Maslow, 1943). However, there was a word of caution which was aired by one student who suggested that they wanted to be able to "discuss more freely with others what happened and what they would have done in the situation without being judged or concerned that the opinion the person has of me may change". This in all reality is difficult to facilitate as it is inevitable that people's perceptions of one another will change over time, so it is vitally important that areas for improvement are addressed by a culture of acceptance and support (Fig. 3.2) which aims to celebrate those people who have been brave enough to identify that a mistake has occurred and are willing to air and share this experience with others so that everyone can learn from them. To assist in developing a safe space, staff often took the first step by using their own personal experiences as a springboard for discussion with the students by sharing stories of their own personal successes and failures, much like village elders sitting around a campfire regaling stories of their pasts to a wide-eyed audience.

\section{Belongingness}

Another benefit of the PTM was the sense of belongingness that it generated. Belongingness is drawn from the hypothesis that humans are driven to make and maintain positive and significant interpersonal relationships (Baumeister \& Leary, 1995). One of the key components to being fully engaged in lifelong learning is high levels of subjective well-being (Huppert \& So, 2013); indeed, a lack of belongingness has been associated with increased stress and even suicidal thoughts (VivekanandaSchmidt \& Sandars, 2018). A culture of belongingness can be developed through the encouragement of reflective practices and the creation of social spaces and activities (Vivekananda-Schmidt \& Sandars, 2018). Chiming with the research which has been conducted at UPDA by Brindley (2016) and Radford \& Hellyer (2016) who have identified the perceived benefits derived from the emotional need to communicate with others, within an organisational setting - an involvement which is driven by the need to share experiences and be accepted, within the boundaries of a secure environment. Research involving students at UPDA resulted 
in a bespoke definition of belongingness in dental education (Radford \& Hellyer, 2016) as a:

deeply personal and contextually mediated experience in which a student becomes an essential and respected part of the dental educational environment where all are accepted and equally valued by each other and which allows each individual student to develop autonomy, self-reflection and self-actualisation as a clinician. (Radford \& Hellyer, 2016, p. 543)

\section{Conclusion}

For students to be successful within their chosen profession there is a requirement to develop higher order thinking skills. The implementation of the PTM assisted with this transition by ensuring that students were no longer solely regurgitating facts or simply displaying adherence to performing set tasks at specific points within their curriculum. By taking the time to draw upon the shared experience of others student confidence increased and attention was focussed on embedding a lifelong approach to learning. The regular PTM afforded students with a space to showcase how they could modify their individual skills and knowledge and apply this to authentic situations in an agile and responsive way within the realms of the real world.

\section{Management of Career Expectations}

Studying degree courses with strong vocational links can be perceived as a fulfilling activity which acts as a vehicle to employment, whilst facilitating an opportunity for individuals to realise their career aspirations in a timely manner following graduation (HEFCE, 2018). Higher graduate employability rates and courses offering degree-level apprenticeships can attract increasing competition for places (Gov.UK, 2019). Having navigated the required hurdles in order to gain a place on a vocationally focussed course, there is an explicit expectation that these students will go onto maintaining high levels of optimism and motivation throughout their studies, especially when undertaking real world activities in outreach placements. 
The downside of moving away from the safe confines of the academic facility to integrate with the future working world is that quite often difficult situations occur which do not always mirror the expected vision of professional practice. It is at this point that encounters, which are a challenge to a novice and conversely seen as routine events to experienced professionals, can in turn be viewed by the student as an aspect in which they are failing to achieve, creating tension and potential dissatisfaction within their chosen career pathway. In addition to this, a pedagogical gap can exist in the espoused prerequisite values related to professional practice and the daily reality of activities students undertake in out-placement locations (Jackson, Garcia-Zambrana, Greenlee, Aujean Lee, \& Chrisinger, 2018).

This highlights the potential benefits of developing professional communities of practice, who are able to lend themselves to supporting the developing professional, by providing a safe space in which to discuss the mismatch between personal expectations and thus empowering the value of real world reality. The importance of diverse group learning (Poole et al., 2018) is that the process facilitates challenges to perceived norms. Indeed, as Eraut (2002) has identified, situated learning is not a prerequisite for local conformity but instead can lead to greater individual variation within their career context.

\section{Putting Development into Perspective}

The challenge of taking a wider and longer perspective of students' development has been met in myriad ways, many of which have their roots in the real world learning tradition. In this sense, real world learning may be highly appropriate if it can be reclaimed from some of the two-dimensional understandings of the term as drawing a spurious distinction between 'study' and 'work', and thus implying that universities are not part of the real world (James, 2015). What must be avoided is a narrow conception of real world learning which only deepens performativity and restricts student academic freedom (Macfarlane, 2016). It can be dangerous to assume that any element of pedagogy, which bears resemblance to practices found in the workplace, are inherently meaningful (e.g. the continued unpopularity of group assessments and how they are assessed). In particular, embarking on graduate-focussed activities without making it 
clear to students why these activities are meaningful and failing to manage these in a meaningful way feels counter to real world learning principles. While many colleagues have found success in applying the principles of real world learning, our second case study would suggest that a staff-student partnership approach which is rooted in negotiating shared expectations, purposes and responsibilities of any academic endeavour. In undertaking a staff-student partnership approach that places expectations and responsibilities on both sides of that dichotomy, a more meaningful engagement is possible.

Staff-student partnership is a concept which has gained significant traction in the UK and internationally in the last decade. The literature on staff-student partnership is a broad church; as an emerging area of practice and study, these principles have been applied in a range of contexts (see Mercer-Mapstone et al., 2017, for a review of the literature). Indeed, much of the conceptualisation encourages a focus on centralising values or principles than specific set of practices (Healey, Flint, \& Harrington, 2014). Few analyses have conceptualised partnership working as a form of real world learning. Certainly, much of the evidence of the benefits of partnership focusses on the skills and employability benefits to students. Real world learning is also based on similar principles around the empowerment of students (https://www.real world learning network.org/real world learning-model/empowerment.aspx). In that sense, a partnership approach would extend this to also empower staff to be more flexible, responsive and authentic in their teaching, support and assessment. In one of the most significant conceptualisations of partnership, Healey, Flint and Harrington describe it as such:

It is [...] about a change in mind-set and attitude to the nature of learning itself, understood as an experiential process of reflection and transformation in relation to oneself and with others. It is about cultural change in the academy, and about embracing the often-disorientating complexity of the contemporary world while maintaining the curiosity. (Healey et al., 2014, pp. 55-56)

The following case study will outline a practical way in which these principles were enacted in order to deliver a meaningful change in staffstudent relationships and to rationalise the use of a real world learning approach. 


\section{Case Study 2}

Negotiating a Shared Understanding and Real World Priorities Through Partnership Learning Agreements (Stuart Sims, Senior Lecturer in Higher Education, University of Portsmouth, Susan Noble, Academic Lead, University of Portsmouth, Amy Barlow, Head of Academic Development, University of Portsmouth, UK)

\section{Context}

This intervention occurred with a Year Two cohort of students in the University of Portsmouth's Fashion and Textile Design course. Lecturers as a group felt they were having difficulty in engaging the students in this year group with much of the standard expectations of the course, and this was having a natural impact upon student attainment and the culture and environment of the course. Previously this course had been highly successful in creating an effective course community, including significant casual interaction across year groups. This was a necessary element of the course as it centralises an authentic, real world learning approach with large portions of teaching and the more general experience of the course taking place in design studios. While containing a range of up-to-date and effective resources, this is naturally a finite space which usually encourages close staff-student collaboration. This Level 5 group then were somewhat of an outlier in that they had not adapted to the culture of the course and this was leading to a range of challenges for staff and students alike.

\section{Intervention}

Through concern about both student well-being and attainment, the course team reached out to the University's central Academic Development Team for support in resolving this issue. A meeting between the course team, academic developers and the Student Union occurred, and a 
multi-stage process was devised to co-create Staff-Student Partnership Agreements.

Particularly common in Scottish Higher Education due to the pioneering work of Sparqs (the Scottish organisation for student partnerships in quality and an affiliate of Quality Assurance Agency Scotland), partnership agreements are designed to publicly acknowledge shared responsibilities and mutual direction of travel between the university and the student body. What distinguishes such documents from similar pieces (e.g. Student Charters) is a commitment to enhancement of quality rather than minimum standards as well as an emphasis on working relationships (Williamson, 2013). Typically, these agreements are signed between a relevant senior member of university staff (e.g. Vice Chancellor and Registrar) and a member of the Student Union's Sabbatical Officer Team (e.g. President and Vice President for Education). Such documents are therefore extensions of existing frameworks of representation at the highest level and set out expectations institutionally. These tend to include value statements, link to other strategic documents and establish baseline expectations for areas such as conduct, provision and support. A critique of such agreements is that they often do not directly engage with staff or students. As such representatives are deciding what they are agreeing to. These agreements may seem opaque or distant to staff and students in their everyday lives. The principles of this particular partnership agreement was adapted in order to reflect more local-level priorities without reliance on the representation typical in institution-wide agreements.

To design a local version of a staff-student partnership agreement, a multi-stage workshop approach was undertaken. The initial workshop was conducted in the Student Union to provide a neutral environment and only included the students. While much of the initial driver was concerns around engagement and behaviour, this was not treated as remedial intervention to only target particular groups-rather a whole year group cohort approach was taken with the intent of fostering a greater sense of course community and belonging. Every student in the second year was invited and the vast majority attended. Drawing on the expertise of the Vice President, Education, a series of warm-up exercises were undertaken to get the participants actively moving and discussing before moving onto the more substantive aspects of the workshop. This 
then progressed to a whole group activity which asked students to reflect on their motivations and priorities around their education. The student group were then asked to stand along the back of the room at particular points to indicate the extent to which they agreed with a set of statements (almost like a living Likert Scale). Explanations of their choices were invited from the group and they were quite forthcoming about why they chose particular views, and this led to in-depth discussions about the support on the course and its links with their employability. The students were then put into groups and asked to outline what they believed their perfect course would look like. The purpose of all these activities was to encourage reflection from the students to give them a clearer idea of what they wanted from the course and beyond as well as how they could achieve this. This progressed into a second stage where members of the course team were invited in and joined a group. Drawing on the previous discussions and facilitated by the Academic Development and Student Union team, each group was invited to outline what their expectations of staff and students would be for the course. The final stage involved a separate workshop day session where students and staff brought together their priorities into a final list of responsibilities for the programme, as identified in Table 3.1:

Table 3.1 Agreed list of staff and student responsibilities

\begin{tabular}{|c|c|}
\hline Students & Staff \\
\hline $\begin{array}{l}\text { - Should turn up to all sessions and } \\
\text { recognise effort put in by tutors } \\
\text { - Should be considerate of space and shall } \\
\text { share/leave space when moving between } \\
\text { rooms } \\
\text { - Should be enthusiastic and positive and } \\
\text { acknowledge what is out of control to } \\
\text { change and good changes we've } \\
\text { experienced } \\
\text { - Take active steps to discuss and resolve } \\
\text { conflicting feedback from different } \\
\text { tutors and find the answers we need } \\
\text { - Be on time and do not disrupt the lesson, } \\
\text { enter quietly or wait outside-respect } \\
\text { those that are learning }\end{array}$ & $\begin{array}{l}\text { - Improve communication about } \\
\text { issues that we raise so that } \\
\text { students understand what action } \\
\text { is taken } \\
\text { - Allow } 10 \text { minutes of feedback } \\
\text { time for student representatives } \\
\text { to talk to wider group } \\
\text { - Reward positive behaviour and } \\
\text { attendance } \\
\text { - Be more transparent about } \\
\text { feedback and how it links to the } \\
\text { marking criteria } \\
\text { - Will start sessions on time even if } \\
\text { students are late }\end{array}$ \\
\hline
\end{tabular}




\section{Conclusion}

In many ways, developing a partnership agreement is quite distinct from values and practices associated with real world learning. However, the drivers behind this intervention were around a sense of shared responsibility and collaboration which are very consistent with this tradition. Universities tend to be values-based institutions, subscribing to a particular agenda of what the purpose of education is and its role in wider society. Bridging the gap between a more liberal conception of the purpose of education and courses that adopt a more real world approach is paramount. Often the function, shape and tradition of universities are unclear to students in a massified system. This is particularly pronounced when students are attending with their future employability as their primary motivation. Engaging with principles of staff-student partnership and real world learning can surface the expectations of both groups. The work presented in this case study has yet to be evaluated fully and therefore it merely serves here as a suggestion of an approach that can address growing concerns across the sector that merges a real world learning and partnership approach. Anecdotally, the staff team reports that the benefits of the partnership agreement have mainly been felt in Staff-Student Consultative Committees where the agreed statements can be used to contextualise course issues or changes as well as holding all participants to account.

\section{Traditional Real World Learning Versus New Approaches}

Traditionally real world learning opportunities have been included within the undergraduate curriculum in specific slices, whereby students engage with a scenario, project or outplacement within a restricted timeframe, with the main focus of course content and assessment being focussed on academic tasks. With the emergence of the Fourth Industrial Revolution (4IR) future generations of students may only spend a few years using the content knowledge which they have acquired during their programmes 
(Hack, 2018). As such, there is an increasingly urgent requirement to consider how we can develop authentic learning pedagogies, which move away the main focus from campus-based delivery, instead allowing a more intent focus on the development of a different skill set which consists of the adaptability, criticality and emotional intelligence which will enable students to evolve into lifelong self-directed learners. Furnishing them with the skills required for a lifetime of continually changing roles, expectations and responsibilities.

In many ways the emergence of higher-level apprenticeships could be perceived as the ultimate real world learning panacea; degree apprenticeships provide students with regular opportunities to engage with the world of work, which is underpinned by an academic base- - to provide structure and tailored interstitial guidance during a student's learning journey.

As flexibility in the ways in which students access their learning increases, there is a need for the curricula to evolve to allow interdisciplinary collaboration and foster authentic learning opportunities which allow students to be endowed with the qualities required not just for lifelong learning within their disciplinary context but to enable the formation of authentic networks in preparedness for the emergence of future super complexity. Critical reflection is a key element that underpins the collaborative element of learning. In our position as educators, we have a responsibility to recreate these values attached to higher education learning. The values of liberal education are often opaque to incoming students, and a more community-orientated approach underpinned by values of partnership is a potential avenue to overcome this disparity. This is particularly pressing in a massified system where large numbers of students are entering with few preconceptions of university or are already internalising a reductionist economically minded transactional understanding of the role that universities play. The real world is more than just work and reducing real world learning to this is to give in to neo-liberal agendas. However, we cannot neglect the economic role that universities have, alongside the associated expectations of students, given the change in funding. As such it is incumbent on academic staff to create a 
community with a sense of mutually developing and evolved values to ensure that all stakeholders are fulfilled. Authentic learning is not solely about meeting the expectations or agendas of institutions, consumers or employers, but it is about creating opportunities to develop and nurture a future skill set which is able to meet the demands of our rapidly evolving society.

Partnership has often been conceptualised as a radical approach to higher education, which rethinks power-relations for the liberation of both staff and students (Wenstone, 2012). Both case study examples were very much rooted in values of reciprocity, trust and community which underpin partnership work (Healey et al., 2014). Although the second case study is situated purely within a university context, the inclusion of the shared case studies aims to acknowledge the importance of developing a collaborative and cooperative approach in supporting real world learning. Indeed, the prerequisites for effective real world learning to occur must be apparent in all stakeholders; the organisation must be keen to pursue, facilitate and support the needs of students, staff and real world stakeholders. The students must demonstrate willingness, ability and engagement with the activities which they are presented with, which must be mirrored by an overarching culture of commitment from real world stakeholders, students and staff to identify and work towards their shared goals. By creating a positive culture, within the architecture of the learning environment, there is an opportunity to share insights and multiple perspectives around learning in a real world context which becomes part of the essence in which to scaffold the foundations of positive educational experience. Failure to integrate these positive attributes into the student experience can lead to the development of a narrow view of the world, which limits the development of practical skills and suppresses empathy and creativity, which, in turn, hampers emotional resilience.

A staff-student partnership approach supported by the development of communities of practice provides all members with both responsibility for the direction of their learning community and also the skills required to engage with it. 


\section{References}

Barnett, R. (2000). Super complexity and the curriculum. Studies in Higher Education, 25(3), 255-265. https://doi.org/10.1080/713696156

Barnett, R. (2017). The ecological university: A feasible utopia. Oxon: Routledge. Baumeister, R. F., \& Leary, M. R. (1995). The need to belong: Desire for interpersonal attachments as a fundamental human motivation. Psychology Bulletin, 117, 497-529.

Boyer, E. (1990). Scholarship reconsidered: Priorities of the professoriate. New York: The Carnegie Foundation for the Advancement of Teaching.

Brindley, J. (2016). The benefits of mentorship for the dental team. British Dental Journal Team, 3, 25-27.

Cameron, D. A., Binnie, V. I., Sherriff, A., \& Bissell, V. (2015). Peer assisted learning: Teaching dental skills and enhancing graduate attributes. British Dental Journal, 219, 267-272. https://doi.org/10.1038/sj.bdj.2015.722

Collini, S. (2012). What are universities for? London: Penguin UK.

Davies, M., \& Kremer, D. (2016). Reflection: How to reduce the risks. Retrieved from http://careers.bmj.com/careers/advice/Reflection\%3A_how_to_ reduce_the_risks

Eraut, M. (2002). Non-formal learning and tacit knowledge in professional work. British Journal of Educational Psychology, 70(1), 113-136. https://doi. org/10.1348/000709900158001

Gov. UK. (2019). Review of post-18 education and funding. Retrieved from https://assets.publishing.service.gov.uk/government/uploads/system/ uploads/attachment_data/file/805127/Review_of_post_18_education_and_ funding.pdf.

Hack, K. (2018). Brave new world-How are we preparing the Next-Generation of learners for the fourth industrial revolution? Retrieved from https://www. advance-he.ac.uk/news-and-views/how-are-we-preparing-the-next

Healey, M., Flint, A., \& Harrington, K. (2014). Students as partners in learning and teaching in higher education. York: Higher Education Academy.

Higher Education Funding Council for England. (2018). Vocational degrees and employment outcomes. Retrieved from https://webarchive.nationalarchives.gov.uk/20180319114826/; http://www.hefce.ac.uk/pubs/year/ 2018/201801/

Huppert, F., \& So, T. (2013). Flourishing across Europe: Application of a new conceptual framework for defining well-being. Social Indicators Research, 110(3), 837-861. https://doi.org/10.1007/s11205-011-9966-7 
Jackson, A., Garcia-Zambrana, I., Greenlee, A. J., Aujean Lee, C., \& Chrisinger, B. (2018). All talk no walk: Student perceptions on integration of diversity and practice in planning programs. Planning Practice \& Research, 33(5), 574-595. https://doi.org/10.1080/02697459.2018.1548207

James, A. (2015). Call the world outside university anything you like, just don't call it 'real' [Blog Post]. Times Higher Education. Retrieved from https://www. timeshighereducation.com/blog/call-world-outside-university-anythingyou-just-dont-call-it-real

Jarvis, P., \& Watts, M. H. (2012). The Routledge International Handbook of Learning. London: Routledge.

Lave and Wenger. (1991). Situated learning: Legitimate peripheral participation. Cambridge: Cambridge University Press.

Macfarlane, B. (2016). Freedom to learn: The threat to student academic freedom and why it needs to be reclaimed. London: Routledge.

Maslow, A. H. (1943). A theory of human motivation. Psychological Review, 50(4), 370-396.

Mercer-Mapstone, L., Dvorakova, S. L., Matthews, K. E., Abbot, S., Cheng, B., Felten, P., ... Swaim, K. (2017). A systematic literature review of students as partners in higher education. International Journal for Students as Partners, 1(1). https://doi.org/10.15173/ijsap.v1i1.3119

Molesworth, M., Scullion, R., \& Nixon, E. (Eds.). (2010). The marketisation of higher education. Oxon: Routledge.

Osterman, K. F., \& Kottkamp, R. B. (1993). Reflective practice for educator: Improving schooling through professional development. Thousand Oaks, CA: Corwin Press.

Poole, G., Iqbal, I., \& Verwood, R. (2018). Small significant networks as birds of a feather. International Journal for Academic Development, 24(1), 61-72. https://doi.org/10.1080/1360144X.2018.1492924

Radford, D. R., \& Hellyer, P. (2016, May 27) Belongingness in undergraduate dental education. British Dental Journal. 220(10), 539-543.

Readings, B. (1996). The university in ruins. USA: Estate of Bill Readings.

Sierbert, S., \& Walsh, A. (2012). Reflection in work-based learning: Selfregulation or self-liberation. Teaching in Higher Education. https://doi.org/1 $0.1080 / 13562517.2012 .696539$

Teaching Excellence Framework. (n.d.). Retrieved from https://www.officeforstudents.org.uk/advice-and-guidance/teaching/what-is-the-tef/

Vivekananda-Schmidt, P., \& Sandars, J. (2018). Belongingness and its implication for undergraduate health professions education: A scoping review. Education for Primary Care. https://doi.org/10.1080/1473987 9.2018 .1478677 
Wenger, E., \& Trayner, B. (2015). Introduction to communities of practice. Communities of Practice and Social Learning Systems. Retrieved from https:// wenger-trayner.com/introduction-to-communities-of-practice/

Wenger, E., Trayner, B., \& De Laat, M. (2011) Promoting and assessing value creation in communities and networks: A conceptual framework. Open Universiteit, Ruud de Moor Centrum. https://doi.org/10.108 0/1360144X.2018.1492924

Wenstone, R. (2012). A manifesto for partnership. National Union of Students (NUS). Retrieved from https://www.nusconnect.org.uk/resources/amanifesto-for-partnership

Williamson, M. (2013). Guidance on the development and implementation of a student partnership agreement in universities. Edinburgh: Sparqs. Retrieved from https://www.sparqs.ac.uk/upfiles/Student\%20Partnership\% 20Agreement\%20Guidance\%20-\%20final\%20version.pdf

Woodall, T., Hiller, A., \& Resnick, S. (2014). Making sense of higher education: Students as consumers and the value of the university experience. Studies in Higher Education, 39(1), 48-67. https://doi.org/10.1080/0307507 9.2011 .648373

Open Access This chapter is licensed under the terms of the Creative Commons Attribution 4.0 International License (http://creativecommons.org/licenses/ by/4.0/), which permits use, sharing, adaptation, distribution and reproduction in any medium or format, as long as you give appropriate credit to the original author(s) and the source, provide a link to the Creative Commons licence and indicate if changes were made.

The images or other third party material in this chapter are included in the chapter's Creative Commons licence, unless indicated otherwise in a credit line to the material. If material is not included in the chapter's Creative Commons licence and your intended use is not permitted by statutory regulation or exceeds the permitted use, you will need to obtain permission directly from the copyright holder.

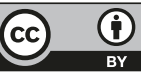

